\title{
La Sanidad Militar en la Guerra de África (1859-1860)
}

\author{
Gómez Rodríguez L. ${ }^{1}$
}

Sanid. mil. 2013; 69 (2): 127-134; ISSN: 1887-8571

\begin{abstract}
RESUMEN:
La guerra con Marruecos (1859-1860) tiene su origen en la constante reclamación de Marruecos sobre la ciudad de Ceuta. Marruecos no aceptó nunca la existencia de una Ceuta española y los incidentes en aquella zona fueron numerosos a través de los siglos. Este trabajo describe la labor que llevó a cabo la Sanidad Militar española en aquella campaña. Son básicas para su conocimiento las obras de los médicos militares Antonio Población y Nicasio Landa que intervinieron en la campaña. Se describen, tras los datos históricos, la organización militar, el desarrollo de las operaciones militares, el estado de la medicina y cirugía de la época, para entender las posibilidades terapéuticas de entonces y, finalmente, la asistencia sanitaria propiamente dicha: plantillas, material sanitario, despliegue de los órganos sanitarios en el teatro de operaciones y la asistencia en hospitales.
\end{abstract}

PALABRAS CLAVE: Ejército de África. Sanidad Militar. Parques de Sanidad Militar. Despliegue de las unidades sanitarias. Ambulancias. Hospitales.

\section{The Medical Service in the African War (1859-1860)}

SUMMARY: The war against Morocco (1859-1860) had its origin in the Moroccan continuous claim over the city of Ceuta. Morocco never accepted the existence of a Spanish Ceuta and there had been a great number of incidents throughout the time. This article describes the work of the Spanish Army Medical Corp during that campaign. The Works of the military medical doctors Antonio Población y Nicasio Landa, who took part in the campaign, had been of paramount importance. After exposing the historical facts, it is described the organization of the Army, the development of the military operations, the state of the art of the medicine and surgery to understand its capabilities and, eventually, the Medical Corp: units, medical material and supplies, deployment of the different levels along the theater of operations and the medical care in hospitals.

KEY WORDS: Army of Africa, Military Medical Service, Medical Supply Depots. Deployment of medical units. Ambulances. Hospitals.

\section{ORIGEN DEL CONFLICTO}

El origen de la guerra de España con Marruecos, que tuvo lugar en los años 1859 y 1860, se encuentra en la ciudad de Ceuta y sus alrededores y se desarrolló en los espacios terrestres y marítimos comprendidos entre Ceuta y Tetuán. Ceuta está situada en el norte de la costa africana del Mediterráneo occidental. Su costa ofrece zonas aptas para fondear y por esta razón fue utilizada desde la remota antigüedad y luego fue base de los berberiscos que durante siglos y hasta el siglo XIX ejercieron la piratería. Precisamente, para combatir la piratería, la Armada portuguesa tomó Ceuta en el año 1415. Ceuta pasó a España en el año 1580, en el reinado de Felipe II, cuando se unieron las coronas de España y Portugal y siguió siendo de España cuando se separaron en 1640, durante el reinado de Felipe IV. Marruecos no aceptó nunca la existencia de una Ceuta española y los incidentes en aquella zona a través de los siglos fueron numerosos y continuos.

${ }^{1}$ Col. Farmacéutico (R).

Dirección para correspondencia: gomezrodriguezl@gmail.com

Recibido: 24 de julio de 2012

Aceptado: 20 de septiembre de 2012
En 1844, reinando ya Isabel II, y por mediación del cónsul inglés en Tánger, se llegó al acuerdo de Tánger de 25 de agosto de 1844 y al convenio de Larache de 6 mayo de 1845 por los que una serie de mojones delimitarían de forma inequívoca la separación entre ambas zonas, la marroquí y la española ${ }^{1}$.

Pasados algunos años, el mando militar español estimó necesaria, para la defensa de la ciudad, la construcción de cuatro fortificaciones. El día 10 de agosto de 1859 se inició la construcción, y durante la noche de ese día, los nativos de la cabila de Anyera destruyeron los trabajos del cuerpo de guardia y también derribaron y rompieron algunos de los mojones que delimitaban la línea fronteriza, alguno de los cuales llevaba grabado el escudo de España. Durante los días siguientes se reprodujeron los incidentes; el gobierno español exigió la reparación de los daños y el castigo de los culpables así como el derecho a fortificar el llano hasta las estribaciones de Sierra Bullones y, como no se obtuvo satisfacción a la demanda, España declaró la guerra el 22 de octubre de $1859^{2}$. El objetivo de la campaña era doble: lograr definitivamente la seguridad de Ceuta y reparar el ultraje recibido. Para lograr este segundo objetivo se consideraba suficiente la conquista de alguna ciudad importante como Tetuán o Tánger. Se optó por Tetuán y se determinó que la ofensiva sería terrestre, para lo cual las unidades de ingenieros construirían una carretera Ceuta - Tetuán que permitiese el paso de armas y bagajes. 


\section{LOS EJÉRCITOS CONTENDIENTES}

\section{El Ejército de África}

Los efectivos del Ejército y la Marina que habían de llevar a cabo las operaciones militares, que recibieron el nombre de «Ejército de África» quedaron fijados por las Cortes el $1^{\circ}$ de octubre de 1859, previa solicitud del presidente del gobierno, Leopoldo O'Donnell, en cien mil hombres, ampliables a ciento sesenta mil si las circunstancias lo exigieran. Después, O'Donnell renunció a la presidencia del gobierno para dirigir las operaciones militares como general en jefe. La composición del Ejército de África era la siguiente:

- Cuartel general del General en Jefe: Teniente General Leopoldo O’Donnell: Estado Mayor, Secretaría de guerra, Planas mayores, Jefaturas de Servicios.

- Primer Cuerpo de Ejército: Mariscal de campo Rafael Echagüe: 11.485 hombres.

- Segundo Cuerpo de Ejército: Teniente General Juan Zabala: 7.259 hombres.

- Tercer Cuerpo de Ejército: Teniente General Ros de Olano: 9.259 hombres.

- División de Reserva: Teniente General Juan Prim: 4.088 hombres.

- División de Caballería: Mariscal de campo Félix Alcalá Galiano: 2.352 hombres.

- Todas estas grandes unidades llevaban Estado Mayor y Secciones de Justicia, Administración, Sanidad y Veterinaria y una unidad de Guardia Civil.

- Armada: Brigadier Segundo Díaz Herrera: Un buque insignia - El reina Isabel II -, noventa y tres barcos, cuatrocientas piezas de artillería y doce mil cuatrocientas toneladas de trasporte ${ }^{3}$.

\section{El Ejército marroquí}

Marruecos tenía un ejército de organización rudimentaria: la infantería estaba constituida por dos grupos, uno de fuerzas regulares, el «Gaix el Medina» y otro de tropas irregulares, «El Gum». Las tropas regulares del Gaix el Medina era un cuerpo de voluntarios reclutados en los núcleos urbanos; El Gum, tropas irregulares, procedían de los pequeños poblados; $\mathrm{Su}$ principal arma, la espingarda, de disparo lento y munición esférica, poco agresiva.

La caballería marroquí estaba formada por la «Guardia Negra» o «Bujaris». Al comienzo de la guerra, en 1859, formaban en esta fuerza de caballería unos quince mil jinetes, armados de sables, gumías, pistolas y espingardas.

La artillería se denominaba «El Tabiya» y estaba formada por un parque de unas setecientas piezas, antiguas, de diversos calibres, cuyo manejo no conocían bien. Así como la caballería marroquí fue un arma eficaz en la campaña, la artillería apenas tuvo protagonismo ni eficacia.

Inicialmente, el ejército musulmán se cifró en cuarenta mil soldados regulares. ${ }^{4}$

\section{DESARROLLO DE LAS OPERACIONES}

\section{Año 1859}

19 de noviembre.- Se inicia la campaña ocupando el «Serrallo», las ruinas de una antigua fortaleza al Oeste del Otero.

20 de noviembre.- Se inicia la construcción de cinco reductos al Oeste del Otero.

25 de noviembre.- Batalla del Serrallo. Es la primera batalla de la campaña. El enemigo intenta sin éxito apoderarse de los reductos a medio construir.

9 de diciembre.- Batalla de Sierra Bullones. Los marroquíes lanzan sucesivos ataques a los reductos Isabel II y rey Francisco. Brava defensa española y retirada enemiga.

\section{Año 1860}

1 de enero.- Batalla de los Castillejos. Arengados por Prim, los españoles atacan bravamente y dispersan al enemigo. Lucharon menos de ocho mil españoles contra veinte mil magrebíes.

6 de enero.- O’Donnell, Prim y Ros de Olano, con veinte mil hombres, siguen su camino hacia Tetuán. Para evitar las alturas de Monte Negrón, intentan atravesar una estrechísima faja de arena que abría paso hacia el sur y quedan atascados durante tres días y cuatro noches por el temporal de levante, Desde entonces, aquella playa se denominó «El campamento del hambre».

14 de enero.- Mejora la climatología. Batalla de Cabo Negro. Orozco empieza a ocupar las primeras alturas de Cabo Negro. La vanguardia española llega al valle de Tetuán. 16 de enero. Se alcanzan sin resistencia el fuerte Martín y el edificio de la aduana.

31 de enero.- Batalla de Torre Geleli o Uad el Jelú. Choque de las caballerías. La infantería española carga a la bayoneta. El enemigo huye despavorido.

3 de febrero.- Desembarco de los Voluntarios Catalanes. Son unos quinientos hombres que quedan encuadrados en el II Cuerpo de Ejército.

4 de febrero.- Batalla de Tetuán. Toman parte veinticinco mil españoles frente a treinta mil marroquíes que defienden Tetuán. La resistencia enemiga se desmorona.

6 de febrero.- Prim con el II Cuerpo de ejército entra en Tetuán.

11 de febrero.- Se inician unas conversaciones de paz que se suspenden sin acuerdo.

7 de marzo.- Desembarco de los tercios vascongados. Unos tres mil hombres.

12 de marzo.- Batalla de Samsa. Seis mil musulmanes intentan sin éxito reconquistar la ciudad.

13 a 21 de marzo.- Nuevas conversaciones de paz sin acuerdo.

23 de marzo.- Batalla de Gualdrás o Uad Ras o Wad-Ras. El enemigo, fuertemente situado en terreno de difícil acceso, a una legua de Tetuán, es desalojado de sus posiciones.

26 de abril.- Se firma el Tratado de paz de Wad-Ras.

Tras la Guerra de África, el Ejército victorioso se instala en un descampado al norte de Madrid, mientras se hacen los preparativos para una entrada triunfal en la capital, que nunca se llevó a cabo. Alrededor del campamento se fueron instalando comerciantes y se creó el barrio conocido hasta hoy como «Tetuán de las Victorias» ${ }^{5,6}$. 


\section{La Sanidad Militar en la Guerra de África (1859-1860)}

\section{MEDICINA Y CIRUGÍA DE LA ÉPOCA}

El Dr. Población cita en su obra la relación de medicamentos que se utilizaron en los botiquines de ambulancias y hospitales de esta campaña ${ }^{7}$. Su clasificación farmacológica nos permitirá valorar con criterios actuales el grado de eficacia de la terapéutica de la época.

\section{Clasificación farmacológica}

Sistema Nervioso Central: Anestésicos: Cloroformo, Éter sulfúrico. Analgésicos o anodinos: Sal de Saturno (Solución acuosa de acetato de plomo), Láudano de Sydenham (Vino de opio compuesto), Píldoras de opio. Excitantes: Té (hojas) Sedantes: Flor de manzanilla.

Sistema circulatorio: Estimulantes cardio-respiratorios: Alcanfor (Aceite volátil de...). Hemostáticos: Agua hemostática o de Pagliari (Benjuí 10 p., Alumbre 20 p., agua 300 p.), Cloruro férrico (sol. Acuosa).

Aparato respiratorio: De acción local: Creosota (Destilado de brea vegetal). Excitantes: Amoniaco líquido (solución acuosa).

Aparato digestivo: Eméticos: Alumbre (Sulfato alumínico potásico), Tártaro emético (Tartrato antimónico potásico), Ipecacuana (Polvo de la raíz). Laxantes: Ácido cítrico en polvo. $\mathrm{Ca}$ tárticos: Crémor tártaro (Bitartrato potásico, Aceite de ricino, Calomelanos al vapor (Cloruro mercurioso), Magnesia (óxido magnésico anhidro) Drásticos: Polvos de jalapa. Neutralizantes: Bicarbonato sódico; Fosfato bicálcico.

Antiinflamatorios: Tisana atemperante Sieu (Cocimiento de cebada y nitro) Antidiarreicos: Laudano de Sydenham (Polvo de opio 10 grs., azafrán en polvo 10 grs., Clavo de especia en grano 10 grs., corteza de Canela 10 grs. Vino blanco, c.s.p. 1000 grs.) Antidisentéricos: Diascordio de Fracastoro (Raíces vegetales y Láudano).

De acción tópica y local: Anodinos: Cerato anodino (Cerato simple, polvo de opio y alcanfor); Tintura de Urticaria (sic). Antiespasmódicos Flor de tilo, Agua de azahar (Flor de naranjo); Astringentes: Emplasto diaquilón (Litargirio y aceite de olivas). Emolientes: Mostaza en polvo, Harina de linaza, Goma arábiga, Polvo de Cantáridas, Flor de malva. Cáusticos: Nitrato de plata cristalizado. Estimulantes locales: Bálsamo samaritano (Vino, aceite y agua), Aceite de Romero. Rubefacientes: Alcanfor. Vesicantes: Asta de ciervo. Vulnerarios: Agua carmelitana (Alcoholado de melisa compuesto), Tintura de árnica, Bálsamo de Malats (Fruto y hojas de balsamina, raíz de sínfito mayor, sumidades de romero, aceite común). Antiflogísticos oftálmicos: Nitrato de plata en solución.

De acción antiséptica. Antisépticos exteriores: Alcohol etílico, Ácido acético medicinal, Licor de Labarraque (Solución acuosa de hipoclorito sódico). Antisépticos Macroparasitarios: Azufre (pomada). Antipalúdicos: Polvos de Quina, Sulfato de quinina (polvo) Antisifiliticos Yoduro potásico ${ }^{8-11}$.

Al repasar la clasificación farmacológica anterior surgen estas consideraciones: En el primer grupo de la clasificación aparecen el cloroformo y el éter. Nos podemos preguntar ¿Se usaron como anestésicos? El cloroformo indudablemente no, ya que la primera anestesia con cloroformo que se llevó a cabo en Europa fue aplicada a la reina Victoria en el parto del príncipe Leopoldo de Sajonia en 1857 y parece poco el tiempo transcurrido para que la técnica llegara a España y estuviera generalizada en 1859. En cambio, el primer cirujano que realizó una intervención con éter en Madrid fue el Dr. Diego de Argumosa y Obregón, el trece de enero de mil ochocientos cuarenta y siete, por lo que era posible que al comienzo de la guerra de África se estuviesen practicando anestesias con éter en Madrid; sin embargo el Dr. Población en su libro «Historia médica de la guerra de África», al explicar las operaciones que se llevaron a cabo en el campo de batalla, alaba el valor con que los heridos soportaban el dolor y cita algunos casos como el de un joven moro llamado Skeri que fue hecho prisionero cuando estaba herido en la articulación húmero-cúbito-radial; se le practicó la amputación del miembro y durante la operación no se le oyó un solo quejido, prueba de que no se utilizaba la anestesia total $^{12}$. Se puede asegurar por tanto que el cloroformo y el éter que figuran en la clasificación se utilizaron como antiemético el primero y como antiespasmódico el segundo.

\section{PERSONAL Y MATERIAL SANITARIO}

\section{Personal}

La Sanidad del Ejército que hizo la guerra de África, se componía de 1 Inspector Director, 1 Subinspector de $1^{\text {a }}$ clase; 4 Subinspectores de $2^{\mathrm{a}}$ clase; 7 Médicos Mayores; 24 Primeros Médicos; 7 Segundos ayudantes; 1 Primer Farmacéutico; 1 Primer ayudante de Farmacia; 1 Segundo ayudante de Farmacia; 2 Farmacéuticos de entrada. Total participantes: 49.

A esta cifra había que añadir los 73 médicos que iban en las pequeñas unidades, regimientos y batallones independientes, $\mathrm{y}$ los tres que acompañaron a la división Ríos, lo que hace un total de 125 profesionales sanitarios para la asistencia sanitaria inmediata y directa de un ejército de 50.000 hombres. Por otra parte, además del personal destinado en las unidades combatientes antes indicado, había que cubrir las necesidades de personal sanitario en los hospitales de Ceuta, Málaga, Algeciras, San Roque, Dos Barrios y otros, por lo que hubo de echar mano del personal destinado en las Capitanías Generales, en las unidades de guarnición en las provincias y en otros centros militares, vacantes que quedaron cubiertas con personal provisional. La plantilla de jefes y oficiales de Sanidad militar en 1859 era de trecientos noventa y nueve profesionales sanitarios de los cuales había cuarenta y nueve sin cubrir. Por otra parte, había que atender las necesidades del ejército desplegado en el territorio nacional, por lo que sólo fue posible el envío a Ultramar de los ciento veinticinco profesionales mencionados. Si la plantilla oficial de Jefes y Oficiales de Sanidad hubiese estado cubierta, el servicio se hubiese desempeñado holgadamente.

Como complemento indispensable, la Dirección de Sanidad nombró numerosos practicantes para los cuerpos de ejército y para los hospitales del litoral. Su número se cifra entre ochenta y noventa, muchos de los cuales eran estudiantes de los primeros cursos de la carrera de Medicina.

Por R.O. de 11 de setiembre de 1859 se crearon las «Compañías Sanitarias», que tenían como misión recoger y evacuar las bajas y prestar servicios auxiliares en los hospitales. Vistos los 
buenos resultados que prestaron estas compañías, fueron reorganizadas con fecha de primeros de enero de 1860, dotándoles de una plantilla más amplia: un Médico mayor Jefe; un Primer ayudante y dos segundos ayudantes, como oficiales médicos para la visita de pacientes; un sargento primero, practicante mayor; treinta y cuatro practicantes de medicina y farmacia; trece clases de tropa para aparatistas y cabos de sala y setenta sanitarios ${ }^{13}$.

\section{Material sanitario}

Tras la declaración de guerra, se hacía necesaria la preparación del material sanitario que debía llevar el Ejército de África. Dicho material comprendía dos grupos. Un primer grupo de material sanitario propiamente dicho, formado por instrumental quirúrgico, material de cura, y material de trasporte de heridos y enfermos, camillas y artolas y un segundo grupo constituido por medicamentos y material de elaboración del servicio de farmacia.

En 1859, año de comienzo de la guerra, el Ejército español no disponía de laboratorio para la preparación de medicamentos ni de parque de material sanitario. La administración de los hospitales militares venía siendo encargada a los «asentistas», personas que contrataban el suministro de medicamentos, material y víveres. Al principio de la campaña hubo de improvisarse todo ${ }^{14}$.

Por lo que se refiere al material sanitario, un médico militar llamado Santiago Rodríguez con un ayudante, Francisco Javier Anguís, habían conseguido prácticamente sin crédito, establecer un depósito de material quirúrgico en el hospital militar de Madrid. Este depósito fue el núcleo para establecer el primer parque de Sanidad Militar, que fue creado por una Real Orden en octubre de 1858 y cuya estructura y obligaciones se fijaron mediante un reglamento posterior en el que se determinaba la plantilla de personal, formada por un director, un primer ayudante, dos practicantes, y dos sirvientes. La Dirección de Sanidad Militar, responsable de preparar el material sanitario del Ejército de África, ordenó en primer lugar la recogida y reparación del material sanitario que estaba almacenado en los parques de artillería e ingenieros; luego, a través de la autoridad militar, ordenó a las unidades de las armas la construcción de mochilas y botiquines para contener el material sanitario que había de usarse en campaña, según el modelo presentado por la Dirección de Sanidad que, al propio tiempo, llevó a cabo diversas adquisiciones, entre las cuales se pueden citar ocho furgonetas-ambulancia, con atalajes, quinientas camillas, cincuenta artolas, cincuenta bolsas de socorro, y numerosas cajas de repuesto. Además, se adquirieron en Paris tiendas-hospitales, ambulancias y otro material sanitario que, por la urgencia del caso no podían ser fabricadas en España. Con este material se dotaron las mochilas-botiquines y bolsas de socorro de las pequeñas unidades, tipo batallón o regimiento, que llevaban instrumentos quirúrgicos, medicamentos y material de cura para el socorro de veinte a cuarenta heridos. Se dotaron también de material sanitario y medicamentos los maletines y cajas de repuesto, de las ambulancias de batallón y de las grandes unidades, brigadas y divisiones, y los hospitales situados en el teatro de operaciones y en la retaguardia. A estas actividades hay que añadir la colaboración entusiasta de toda la Nación que abría sus arcas para colaborar al gasto de las adquisiciones y confeccionaba material de cura, hilas, vendas y compresas que, en cantidades fabulosas, enviaba desde pueblos y ciudades. Así cantaba esta patriótica actitud el «Romancero de la guerra de África»: "Vayan al suelo africano/ hilas compresas y vendas/ Son de afecto pura ofrenda/ de nuestro amor castellano». A estos efectos, Castilla era España toda.

El abastecimiento de material durante la campaña se llevó a cabo en dos fases: en la primera fase, como se ha indicado, se concentró el material adquirido, fabricado o recuperado en el Parque de Sanidad, de nueva creación. Desde allí se remitía a un parque sanitario de acumulación situado en Alicante que se encargaba de distribuirlo a los depósitos establecidos en los puertos de Cádiz, Algeciras y Málaga, y desde estos puertos peninsulares se abastecían los diversos parques sanitarios que progresivamente fueron establecidos, a medida que progresaba la ofensiva, en Ceuta, El Serrallo, Aduana de Río Martín y Tetuán (Fig. 1 y 2). Estos parques abastecían los repuestos de los cuarteles generales de las grandes unidades desde los cuales se abastecían los botiquines de las pequeñas unidades ${ }^{15,16}$.

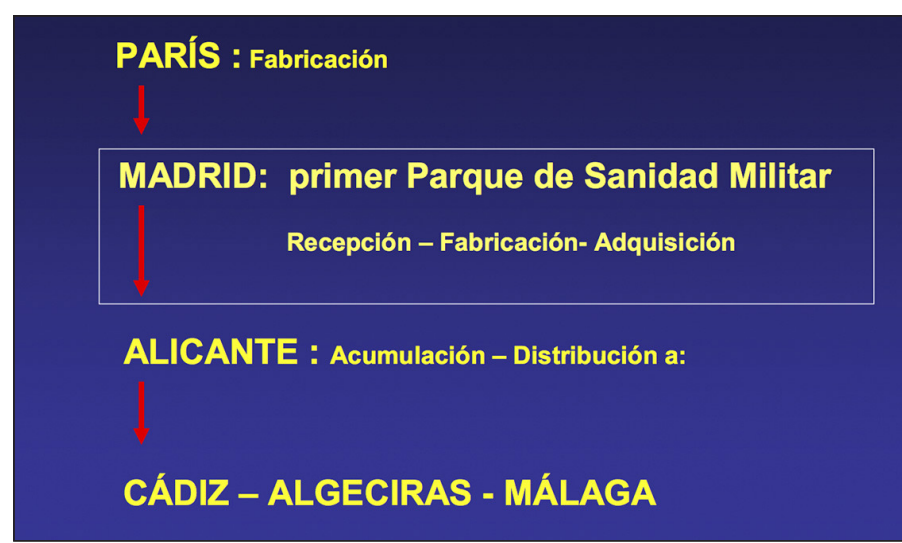

Figura 1. Abastecimiento de material sanitario ( $1^{a}$ Fase)

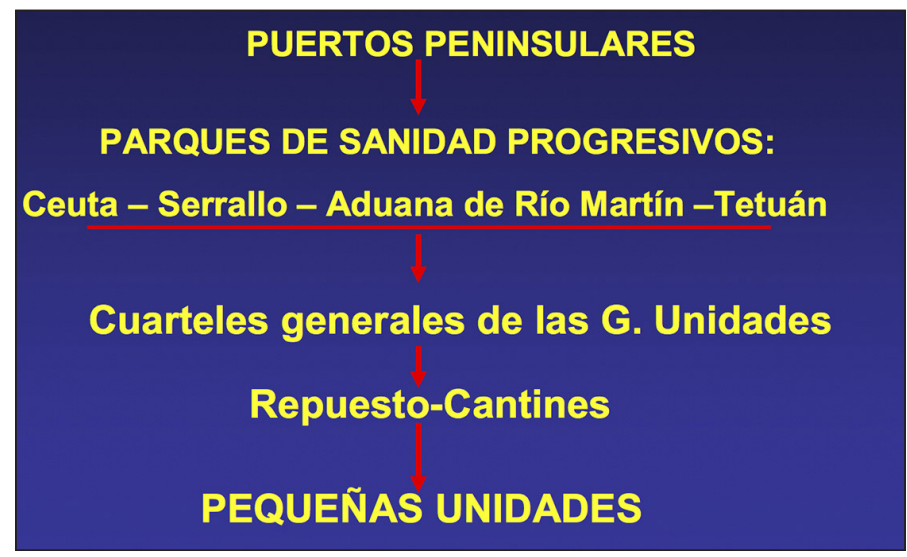

Figura 2. Abastecimiento de material sanitario ( $2^{a}$ Fase).

\section{LA ASISTENCIA SANITARIA DURANTE LA CAMPAÑA}

\section{Número de bajas en acción de guerra}

El número de bajas se refleja en la Tabla 1. En realidad, estas cifras se han de tomar como aproximadas, pues en las diversas obras consultadas aparecen datos diferentes. Incluso hay un historiador de reconocido prestigio como Raymon Carr que habla de 70.000 bajas, cuando los efectivos del ejército expedicionario eran unos cincuenta y cinco mili ${ }^{17}$. 
Tabla 1. Bajas españolas en cción de guerra en la Guerra de África (1859-18609).

\begin{tabular}{|lcc|}
\hline Batallas & Muertos & Heridos \\
\hline Del Serrallo & 89 & 336 \\
De Sierra Bullones & 80 & 300 \\
De los Castillejos & 150 & 650 \\
De Guad el Jelu o Torre Geleli & 80 & 500 \\
De Tetuán & 200 & 915 \\
De Samsa & 22 & 300 \\
De Uad Ras & 140 & 1.200 \\
Otras acciones & 391 & 793 \\
\hline Total de bajas en acción de guerra & 1.152 & 4.994 \\
\hline
\end{tabular}

\section{Táctica sanitaria}

Siguiendo las normas tradicionales del despliegue sanitario se establecieron tres líneas de acción: una primera línea para recoger los heridos y prestarles los primeros auxilios, de lo que se encargaban las ambulancias de batallón o brigada; una segunda línea para consolidar las curas, realizar las operaciones quirúrgicas urgentes y poner los heridos en estado de evacuación, de lo que se encargaban las ambulancias de brigada o de división según los casos, que se constituían en hospitales de sangre; y una tercera línea de acción para proseguir la curación, y vigilar los heridos hasta su recuperación, de los que se ocupaban los hospitales fijos situados fuera del teatro de operaciones.

En el esquema que se presenta a continuación figura el despliegue de los órganos sanitarios en la guerra que nos ocupa. Se distinguen dos casos: en el primero se expone el despliegue en terreno montañoso; en primera línea actuaron las ambulancias de batallón que eran sencillas y dotadas de flexibilidad y movilidad, cualidades que permitían moverse en terreno abrupto y situarse muy cerca de donde tenía lugar la batalla. A estas ambulancias de batallón las denominó el Dr. Población «guerrillas» porque se movían, aparecían y desaparecían, como los famosos guerrilleros de la guerra de la Independencia. La segunda línea en zona montañosa era la ambulancia de brigada y la tercera línea tenía dos opciones: en los primeros combates, que se desa-

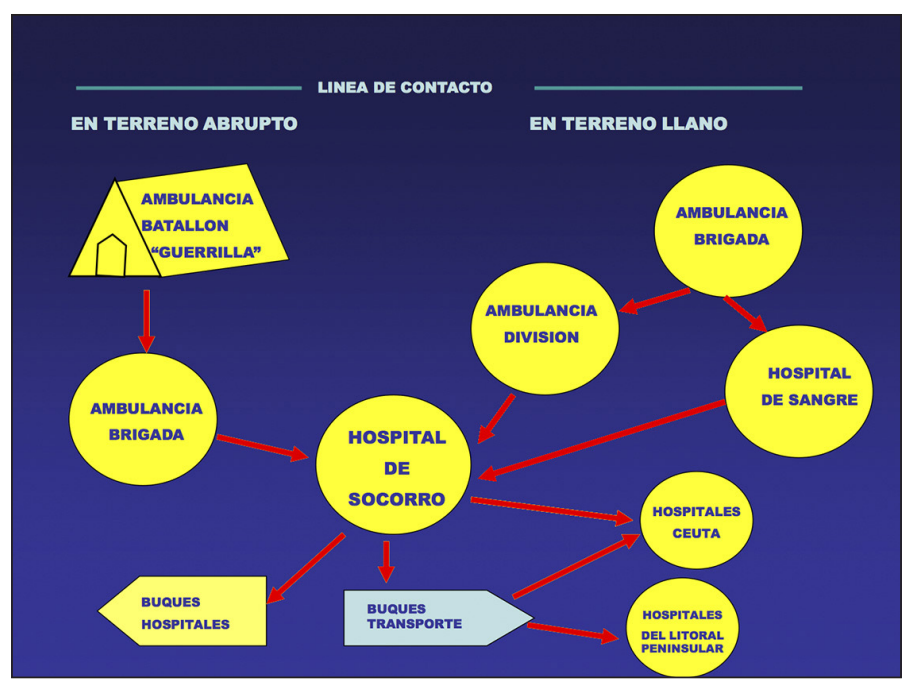

Figura 3. Despliegue de los órganos sanitarios. rrollaron cerca de Ceuta, las batallas del Serrallo y sierra Bullones, los hospitales de Ceuta actuaron como de tercera línea; pero más tarde, cuando la distancia a Ceuta era mayor, hicieron ese papel los hospitales de campaña, entonces llamados «hospitales socorro», que se organizaron en el cuartel general de cada cuerpo de ejército. La evacuación se hacía por tierra desde los citados hospitales hacia los hospitales de Ceuta, por la carretera que iban abriendo los ingenieros del Ejército de África. En el despliegue sanitario en terreno llano y evacuación por mar, las ambulancias de brigada iban en primera línea; en segunda línea, las ambulancias de división que, a veces, se constituyeron en hospitales de sangre de mayor capacidad, dado el número de combatientes que entraron en combate y el mayor número de bajas, como ocurrió en las batallas de Tetuán y Uad-Ras. En la tercera línea había dos opciones condicionadas por el estado de la mar: si la mar estaba en calma, se podía llevar a cabo la evacuación sin problemas desde el hospital de campaña a los buques transporte que desde la playa de río Martín trasportaban los heridos a los hospitales del litoral peninsular español, o a los buques hospitales situados en la mencionada playa; pero si había «levante», que hacía imposible la evacuación, se establecían como tercera línea las llamadas «tiendas hospital» cercanas a la playa y se esperaba que pasase el «levante». A veces, se destinaron a esta misión, en lugar de las tiendas hospital, las chozas de los aduares situados cerca de la mencionada playa ${ }^{18}$.

\section{Las heridas}

La gravedad y el tratamiento de las heridas dependen, como es natural, del arma que las provoca. Las armas de fuego del ejército marroquí eran la espingarda y la artillería, y el arma blanca por excelencia, la gumía. La espingarda era una especie de tosco fusil de fabricación artesanal, de largo cañón, ánima lisa, llave de chispa y pequeño calibre, cuyos proyectiles eran de plomo y forma esférica, aunque en ocasiones eran de postas y tenían forma de dado. Los marroquíes carecían de artillería eficaz, aunque, como antes se ha dicho, tenían muchos cañones de modelo anticuado y diferentes calibres y sólo para defensa de plazas o posiciones fortificadas; pero carecían de artillería de campaña. Su artillería resultó inútil en la campaña y sólo fue utilizada con escasos disparos en la batalla de Tetuán, el 4 de febrero, aunque en aquella ocasión causó graves daños en las tropas españolas. Así que el arma por excelencia era la espingarda.

Las lesiones producidas por la espingarda fueron de tres clases: cuando el disparo era hecho a quemarropa, era mortal de necesidad si alcanzaba una zona vital, cabeza, pecho o vientre; en la distancia media, el proyectil contorneaba a veces los huesos y si no encontraba en su trayectoria un órgano vital, salía al exterior sin causar una herida grave; a larga distancia, el proyectil, incapaz de herir, producía únicamente contusiones; de esta forma, los servicios sanitarios de vanguardia podían calcular de antemano con alguna precisión la clase de las bajas según se planteaba la batalla. Ello explica también el gran número de contusiones que sufrieron las tropas españolas. Es de consignar que, salvo rarísimas excepciones, todas las heridas fueron recibidas de frente, es decir, de cara al enemigo, lo que habla muy alto a favor de nuestros soldados. 
Si el conjunto de heridas contusas fue numerosísimo, el número de heridos por arma blanca fue muy reducido porque, en los combates cuerpo a cuerpo en los que se utilizaban estas armas, la bayoneta calada en el fusil español daba una gran superioridad frente a la gumía. Las heridas que producía la gumía eran generalmente de cabeza y en bastantes casos limpias y de poca gravedad. Sí hubo casos de ensañamiento con arma blanca a soldados previamente heridos por arma de fuego ${ }^{19}$.

\section{Las curas en primera y segunda fila}

El romancero de la guerra de África, al que anteriormente se ha aludido, describe en cuatro versos las curas en primera línea: «De rodillas Esculapio/ fibras ata y une huesos/desnuda tierra, harta de agua/tiene el paciente en su lecho» ${ }^{20}$.

Para el cumplimiento de su misión, las ambulancias de batallón, acompañadas de su médico, llevaban mochilas-botiquines dotadas de suficientes piezas de apósitos, vendajes, medicamentos y material quirúrgico para el socorro de veinte a veinticuatro heridos, camillas tipo Anel, y cubetas para agua; las ambulancias de brigada llevaban un primer médico, los oficiales médicos de los batallones que componían la brigada, dos o más practicantes de Sanidad Militar, y los de las unidades de la brigada. El material se componía de una mochila botiquín, un maletín con instrumental quirúrgico y farmacéutico, bolsas para material de socorro, que los practicantes llevaban puestos en bandolera, cubetas para agua, camillas, artolas, furgones, y cajas de repuesto de material quirúrgico y farmacéutico y tiendas de campaña. Las ambulancias de división llevaban el doble de personal y material de las brigadas.

Para la curación de las heridas, aunque cada médico utilizaba los medicamentos de la dotación que consideraba convenientes, había un formulario tácito que se resume a continuación:

- En contusiones: hilas empapadas en tintura de árnica, de belladona, emolientes o fomentos de agua sedativa.

- En quemaduras: hilas empapadas en tintura de urticaria (sic) del Dr. Somolinos.

- En heridas simples: Bálsamo samaritano o de Malás.

- En heridas sangrantes: agua hemostática o percloruro de hierro.

- En heridas de bala con orificios de entrada y salida: aplicación de apósitos empapados en bálsamo samaritano y sujetos con vendaje.

- En hemorragias: restañar la sangre con nitrato de plata.

- En úlceras extensas y fétidas: Licor de Labarraque ${ }^{21}$.

\section{El problema del cólera}

El Ejército de África tuvo que hacer frente a dos enemigos, al Ejército marroquí y a un enemigo invisible: el cólera. La magnitud del problema en general y del hospitalario en particular que el cólera planteó, puede deducirse de los siguientes datos: el total de bajas en acción de guerra alcanzó la cifra de 6.146 , entre muertos y heridos como se ha indicado anteriormente, mientras que las bajas por cólera fueron 12.500 de los que 2.377 fallecieron $^{22}$. Aun teniendo en cuenta las diferencias existentes en los datos de unos y otros autores, las cifras hablan por sí solas.

Los primeros casos de cólera aparecieron en el Serrallo, cuando el ejército expedicionario desembarcó en Ceuta y enseguida empezaron a multiplicarse. Luego se extendió rápidamente y el veinticinco de noviembre de 1859 había afectado en mayor o menor intensidad al sesenta por ciento de los efectivos del Primer Cuerpo de Ejército y fue afectando sucesivamente al Segundo Cuerpo de Ejército, a la División de reserva y al Tercer Cuerpo de Ejército, que acampó el catorce de diciembre de dicho año en el Tarajal, un campamento húmedo y malsano. La enfermedad afectó también a los mandos: los generales Prim, García, Ros de Olano, y al personal sanitario, entre los cuales se encontraba el Inspector de Sanidad Dr. Anel, y causó algunas defunciones como la del médico mayor José Roger Pedrosa, el primer ayudante Antonio Muñoz y el segundo ayudante Isidro Sastre Storch y tuvo su flujo y reflujo en el tiempo que duró la campaña; hubo días en los que se registraron doscientos cincuenta y cuatro casos con sesenta y dos defunciones; a mediados de enero de 1860 había desaparecido prácticamente y luego reapareció al final de la campaña en la División Ríos, que llegaba a cubrir bajas. El tratamiento, con los medios terapéuticos al alcance, consistía fundamentalmente en infusiones de manzanilla o té, tisana atemperante, sexquicloruro de hierro (cloruro férrico), cocimiento blanco diascordiado y lavativas amiláceas laudanizadas; el láudano en infusiones fue un tratamiento precioso así como el arroz laudanizado, las píldoras de opio y las infusiones con gotas de cloroformo ${ }^{23}$.

Otros de los graves problemas que planteó el cólera fue la evacuación. Se planteó el dilema de si evacuar los enfermos a la península, con el peligro de encender allí nuevos brotes aunque algunos médicos negaban la posibilidad de contagio, u hospitalizarlos en Ceuta. Se adoptó esta segunda posibilidad a base de improvisar barracones y habilitar para los enfermos convalecientes un bergantín anclado en el puerto de aquella ciudad ${ }^{24}$. Así todo, fue necesario evacuar un cierto, aunque reducido, número de enfermos a la península y esos casos dieron lugar a una negativa reacción sociológica en la Península.

\section{Los hospitales}

Durante la campaña, hubo hospitales en Ceuta y en el litoral peninsular; se utilizaron buques como hospitales flotantes y, en los últimos días de la campaña se abrieron hospitales en Tetuán (Fig. 3).

Ceuta era toda la ciudad un hospital; los soldados salieron de los cuarteles y los clérigos de sus iglesias; se habilitaron edificios públicos como el casino o el Rebellín, un antiguo edificio. Según las necesidades, se clasificaron en tres grupos: para coléricos, para heridos y para convalecientes. Se dedicaron a coléricos: el de los Reyes, con 707 camas; el de San Francisco, con 80 camas; el de Jesús y María, con 80 camas; y los de San Manuel, El Reloj, Artillería, La Catedral, y la Trinidad, que sumaban entre los cinco 600 camas. Para heridos se instaló en el casino un hospital con 25 camas, dedicado a oficiales y otro en el Rebellín para tropa con 350 camas. En unos barracones de madera construidos a las afueras de la ciudad se instalaron 100 


\section{La Sanidad Militar en la Guerra de África (1859-1860)}

camas que se repartieron entre convalecientes coléricos, como se ha dicho, y convalecientes heridos en espera de repatriación.

En estos hospitales faltaba de todo; faltaban médicos, pero sobraba abnegación y entusiasmo en los que allí había y en los médicos de los estados mayores de las grandes unidades que acudieron solícitos para ayudarlos; faltaron enfermeros, pero allí estaban los presidiarios dispuestos a prestar su ayuda; faltaban utensilios, pero las tropas dejaron el suyo. Así se fue remediando la necesidad hasta que fueron llegando de España el personal y material que con toda urgencia se demandaba. En esta organización improvisada destacó el Dr. Martrús, que durante toda la campaña estuvo como médico jefe al frente de los servicios médicos de todos los hospitales de Ceuta, y cuya infatigable actividad permitió que en las primeras semanas de diciembre estuvieran en funcionamiento los hospitales que antes se ha indicado, a pesar de que, a imitación de Francia, era la Administración Militar la encargada de instalar organizar y dirigir los hospitales militares. El Servicio farmacéutico de todos estos hospitales estaba a cargo del boticario militar don Juan de Tapia. La botica militar estaba aneja al hospital de los Reyes y una vez pasada la visita médica, allí confluían los practicantes de farmacia de todos los hospitales con sus libretas que contenían las correspondientes prescripciones. Puede calcularse en qué cantidad habían de hacerse todas las preparaciones con sólo saber que esta era la única farmacia que había en Ceuta y que atendía no sólo a todos los hospitales, sino también a los militares de la guarnición y a los civiles de la población. Ayudaban al señor Tapia los farmacéuticos destinados en los cuarteles generales y, a pesar del gran trabajo, nunca llegaron a faltar medicamentos ni la buena calidad de los mismos y los profesionales de los hospitales tuvieron amplia facultad para recetar lo que estimaron necesario.

Cuando las tropas españolas entraron en Tetuán, se estableció un hospital en una pequeña mezquita que, una vez reformada, quedó habilitado para hospitalizar 300 pacientes y dotado de servicio de farmacia y demás dependencias necesarias. Allí se habilitó también un espacio para alojar el Parque de Sanidad trasladado desde la Aduana, un edificio cerca de la desembocadura de Río Martín donde estuvo instalado anteriormente. Para los enfermos coléricos, cuyo número había aumentado en la última fase de la campaña, se habilitó un edificio frente al anterior y para oficiales el consulado inglés.

Para hospitales flotantes se contrataron por el gobierno cuatro vapores de hélice: El Barcelona de 1.200 toneladas y con 200 camas; el Torino (Piamontés) de 2.000 toneladas y con 500 camas; el Cataluña de 1.500 toneladas y con 500 camas y el Ville de Lyón (francés) de 2.500 toneladas y con 600 camas.

Los dos primeros se destinaron a heridos y enfermos comunes y los dos segundos para coléricos. En cada buque iban uno o dos médicos, un farmacéutico o practicante de farmacia, y cinco practicantes de medicina $y$, como material sanitario un botiquín.

Estos barcos hospital, destinados a su inicial cometido, hubieran bastado, pero como no fue así hubo de aprovecharse de pequeños barcos que con cualquier motivo salían para Ceuta, como el Mallorquín, el San Bernardo, el Bretagne, el Pensa- miento, el Vigilante y otros. Cuando iban a zarpar, si tenían espacio, izaban en el palo mayor una bandera amarilla, que era la señal que lucían los hospitales militares para que desde la playa se iniciase la evacuación.

Las evacuaciones se hacían hacia los hospitales del litoral establecidos en Algeciras, Cádiz, Málaga y alrededores. Estas evacuaciones se hicieron siempre en deplorables condiciones: apiñamientos, frío, balanceo, rachas de agua y viento que afectaban sobre todo a los que iban en cubierta, pues fue necesario aprovechar el espacio al límite. Además, la organización de las evacuaciones corría a cargo de la Administración, sin tener en cuenta que lo acertado hubiese sido encargar de ello a la Sanidad que podía decidir con mejor criterio el quién, cuándo y cómo y otras condiciones de la evacuación ${ }^{25}$.

De todo lo dicho anteriormente se deduce que el denodado esfuerzo de la Sanidad Militar española en la Guerra con Marruecos (1859-1860) fue altamente eficaz, muy sacrificado $\mathrm{y}$, en muchos casos, heroico. La reina Isabel II premió dicha actuación equiparando en derechos y deberes a los oficiales de la Sanidad Militar con los de las Armas ${ }^{26}$.

\section{BIBLIOGRAFIA}

1. Martín Gómez A. L. (2009 a) "Los combates de Ceuta. Guerra de África 1859-1860»Almena Ediciones. Madrid. 7 ss.

2. Acaso Deltell S. (2007 a) «Una guerra olvidada. Marruecos 1859-1860» Inédita editores. Barcelona. 31 ss.

3. Martín Gómez A. L. (2009 b) o. c., 59-62.

4. Martín Gómez A. L. (2009 c) o. c., 54-55.

5. Acaso Deltell S. (2007 b) o. c., 66-194 passim.

6. Alarcón P. A. (1861 a) "Diario de un testigo de la guerra de África» Linkgua ediciones S.L. Barcelona. 176 ss.

7. Población y Fernández A. (1860 a) «Historia médica de la guerra de África» Madrid. 34-35.

8. Diccionario Terminológico de Ciencias médicas (1978) Undécima edición. Salvat editores. Madrid.

9. Formulario español de Farmacia militar (1948) Séptima edición. Publicaciones del Laboratorio y Parque Central de Farmacia Militar. Madrid.

10. Farmacopea española $7^{\mathrm{a}}$ edición. Madrid 1905.

11. Buchan J. (1775) «Tratado Completo del método de precaver y curar las enfermedades» Apéndice XXXIV Madrid.

12. Población y Fernández A. (1860 b) o. c., 204.

13. Población y Fernández A. (1860 c) o. c., 20-24.

14. Vives y Noguer I. et al. (1898) «El Laboratorio Central de Sanidad Militar. Memoria histórico-descriptiva» Imprenta del Cuerpo Administrativo del Ejército. Madrid. 19.

15. Población y Fernández A. (1860 d) o. c., 16-18.

16. Landa N. (1860 a) «La campaña de Marruecos. (1859-1860). 2 $2^{\text {a }}$ Edición. Algazara S.L. Málaga, 2008. 67-69.

17. Massóns Esplugas J.M. (1994 a) «Historia de la Sanidad Militar española» Ed. Pomares Corredor S.A. Barcelona. II, 223.

18. Población y Fernández A. (1860 e) o. c., 25 ss.

19. Massóns Esplugas J.M. (1994 b) o. c., II, 225.

20. Harzenbusch J.E. (1860) «Cancionero de la guerra de África» Imprenta y estereotipia de M. Rivadeneyra. Madrid. 175.

21. Población y Fernández A. (1860f) o. c., II, 171 ss.

22. Massóns Esplugas J.M. (1994 c) o. c., II, 224.

23. Población y Fernández A. (1860 g) o. c., 110.

24. Massóns Esplugas J.M. (1994 d) o. c., II, 224.

25. Landa N. (1860 b) o. c., 57 ss.

26. Ley de 20 de marzo de 1860 . 